\title{
PENICILLAMINE-RELATED LICHENOID DERMATITIS AND UTILITY OF ZINC ACETATE IN A WILSON DISEASE PATIENT WITH HEPATIC PRESENTATION, ANXIETY AND SPECT ABNORMALITIES
}

\author{
L. LEGGIO, A. FERRULli, A. MIRIJELLO, L. ABENAVOLI, D. DI GIUDA ${ }^{1}$, \\ S. FUNICIELLO ${ }^{2}$, M. ROTOLI ${ }^{3}$, G. GASBARRINI and G. ADDOLORATO \\ Institute of Internal Medicine and Institute of ${ }^{1}$ Nuclear Medicine, Catholic University of Rome; ${ }^{2}$ Orphan \\ Europe Srl, Segrate, Milan; ${ }^{3}$ Dermatology Institute, Catholic University of Rome, Rome, Italy
}

Received June 20, 2006 - Accepted November 8, 2006

Wilson disease is an autosomal recessive disorder of hepatic copper metabolism with consequent copper accumulation and toxicity in many tissues and consequent hepatic, neurologic and psychiatric disorders. We report a case of Wilson disease with chronic liver disease; moreover, in our patient, presenting also with high levels of state anxiety without depression, ${ }^{99 \mathrm{~m}} \mathrm{Tc}-\mathrm{ECD}-\mathrm{SPECT}$ showed cortical hypoperfusion in frontal lobes, more marked on the left frontal lobe. During the follow-up of our patient, penicillamine was interrupted after the appearance of a lichenoid dermatitis, and zinc acetate permitted to continue the successful treatment of the patient without side-effects. In our case the therapy with zinc acetate represented an effective treatment for a Wilson disease patient in which penicillamine-related side effects appeared. The safety of the zinc acetate allowed us to avoid other potentially toxic chelating drugs; this observation is in line with the growing evidence on the efficacy of the drug in the treatment of Wilson disease. Since most of Wilson disease penicillamine-treated patients do not seem to develop this skin lesion, it could be conceivable that a specific genetic factor is involved in drug response. Further studies are needed for a better clarification of Wilson disease therapy, and in particular to differentiate specific therapies for different Wilson disease phenotypes.

Wilson disease (WD) is an autosomal recessive disorder of hepatic copper metabolism with consequent copper accumulation and toxicity in many tissues and consequent hepatic, neurologic and psychiatric disorders (1-2).

The pharmacological approach in WD includes D-penicillamine, trientine, tetrathiomolybdate and zinc (1-2). According to Roberts and Schilsky (3), only chelating agents (penicillamine or trientine) should be used in symptomatic patients, while zinc may be used in pre-symptomatic patients and in the maintenance therapy of successfully treated symptomatic patients. However, at present, the most appropriate therapy remains controversial in WD and descriptions in literature reflect different preferences according to specific experiences and the physician's opinion (4).

With regard to penicillamine-treated patients, several side effects may appear, including skin disorders as cutis laxa, elastosis perforans serpingiosa, pemphigus and lichenoid dermatitis (2). In these cases penicillamine must be interrupted, but

Key words: Wilson disease, lichenoid dermatitis, penicillamine, zinc acetate, trientine, SPECT abnormalities

Mailing address:

Dr Lorenzo Leggio, MD,

Institute of Internal Medicine,

Catholic University of Rome, Gemelli Hospital,

L.go Gemelli 8, 00168 Rome, Italy

Tel: + $390630154334 ;$ Fax: + 390635502775

e-mail: g.addolorato@rm.unicatt.it 
no conclusive data are present in literature on the possible "second choice" drug for WD patients.

We report a WD case with hepatic presentation, anxiety and cerebral perfusion abnormalities at Single-Photon Emission Computed Tomography (SPECT) abnormalities, where penicillamine was interrupted after the appearance of a lichenoid dermatitis and zinc acetate permitted to continue the successful treatment of the patient without sideeffects.

\section{MATERIALS AND METHODS}

A 27-yr old Slav woman was admitted to our Department of Internal Medicine in 1999, presenting with asthenia and fatigue; moreover, high levels of anxiety without current depression were evidenced by psychometric evaluation, performed according to Spielberg et al (5) and Zung et al (6), as also previously described in our laboratory (7-8). Clinical, instrumental, laboratory and histological data evidenced a chronic active hepatitis; the diagnosis of WD was made, considering the high values of copper both in urine and in liver biopsy, excluding other possible causes of chronic active hepatitis. Neurologic clinical examination was normal. Brain Magnetic Resonance Imaging (MRI) did not show copper accumulation in the basal ganglia, while SPECT examination with ${ }^{99 \mathrm{~m}} \mathrm{Tc}$-Ethyl-Cysteinate-Dimer (ECD) demonstrated regional cortical hypoperfusion in frontal lobes (Fig. 1). The patient was treated with penicillamine $(750 \mathrm{mg} / \mathrm{die})$ with improvement of both symptoms and hepatic serological tests.

In 2003 the patient presented irregularly rounded erythematous lesions of non-photoexposed skin, located on the abdominal cutis and in particular in the umbilical region (Fig. 2). The macroscopic characteristics of these skin lesions, as well as the presence of pruritus, were highly suggestive of lichenoid dermatitis, as confirmed by the skin biopsy (Fig. 3).

\section{RESULTS}

In consideration of the appearance and diagnosis of lichenoid dermatitis in our WD patient, penicillamine was interrupted and the patient started zinc acetate $(150 \mathrm{mg} /$ die $)$. We chose to use zinc acetate in view of its safety and manageability (9). After the interruption of penicillamine, a progressive disappearance of the skin lesion was observed and no other therapies were needed, such as corticosteroids and/or intravenous immunoglobulins (10).
The patient has been evaluated every 6 months (the last time in May 2006); the main clinical and serological parameters were steady and no skin lesion and/or other side-effects have appeared.

In the present case describing a WD patient with hepatic presentation, anxiety and SPECT abnormalities, zinc acetate was useful in continuing the treatment of the disease after the appearance of penicillamine-related lichenoid dermatitis.

\section{DISCUSSION}

Penicillamine-related side effects can be direct (e.g. pyridoxine deficiency, cutis laxa, elastosis perforans serpingiosa) or immunologically mediated, (e.g. bone marrow suppression, lupus erythematosus, immune complex nephritis, pemphigus, lichen planus, myasthenia gravis) (2). In particular, in the immunologically mediated mechanism, penicillamine acts by changing surface antigens and precipitating an immune response to epidermal neoantigens. This last aspect is according to the growing evidence showing the importance of the surface antigens in the cellular mechanisms of the skin (11).

Lichen planus, an inflammatory mucocutaneous condition with characteristic violaceous polygonal flat-topped papules and plaques (12-13), whether apparently idiopathic, drug-induced due to graft-versus-host reaction or related to intestinal malabsorption as celiac disease (14), may represent a cell-mediated immune response to an induced antigenic change in the skin or mucosa (15). Penicillamine represents a well-known drug able to cause lichenoid mucocutaneous lesions (16). These skin lesions are present in several diseases treated by penicillamine, such as rheumatoid arthritis (17) and primary biliary cirrhosis (18). However, to the best of our knowledge there are no data on penicillamine treated WD patients developing licheonoid lesions. This could be related to the hypotheses of lichen planus as autoimmune disease (15), supporting the higher frequency of lichenoid lesions in penicillamine-treated patients with autoimmune diseases.

Since WD needs a longlife-long treatment to prevent liver damage due to the copper accumulation and the consequent toxicity (19), it was compulsory 
to start an alternative drug for WD. In our case the therapy with zinc acetate represented an effective treatment for a WD patient in which penicillaminerelated side effects appeared, and the safety of the zinc acetate allowed us to avoid other potentially toxic chelating drugs (21). This observation is in line with the growing evidence on the efficacy of the drug in the treatment of WD $(9,20,22)$. Currently, the use of zinc in WD is limited to long-term maintenance treatment $(9,22)$. However, recently Marcellini et al (23) reported a 10-year zinc therapy followup, suggesting zinc as the treatment of choice in pre-symptomatic pediatric patients. According to Marcellini et al, Hoogenraad recently published a "paradigm shift" in the treatment of WD, suggesting zinc therapy as the drug of choice (24).

Finally, our patient showed brain perfusion abnormalities at SPECT examination. Using the same technique, Giagheddu et al (25) showed decreased uptake of ${ }^{99 \mathrm{~m} T c-E C D}$ in several cortical areas and/or subcortical structures of patients with $\mathrm{WD}$, suggesting a possible role of this neuroimaging tool in the monitoring of the disease. Hypotheses have been recently made on the pathological role of regional cerebral blood flow for the basal ganglia, that represent the classical neurological area involved in the copper accumulation in WD (26). Moreover, a correlation between SPECT perfusion abnormalities and neurologic and/or psychiatric symptoms have been described in WD (27-30).

In our patient, presenting with high levels of state anxiety without depression, ${ }^{99 \mathrm{~m}} \mathrm{Tc}-\mathrm{ECD}-$ SPECT showed cortical hypoperfusion in frontal lobes, more marked on the left frontal lobe (Fig. 1). No perfusion abnormalities were detected in the basal ganglia. Similar cortical cerebral blood flow abnormalities have been frequently reported in patients suffering from different psychiatric disorders (31). Consequently, it is possible to hypothesize that anxious-neurotic behaviour may be related to cerebral perfusion changes, as recently shown by our group in celiac patients (32). This hypothesis is supported by data showing a relationship between anxiety disorders and frontal cortex hypoperfusion

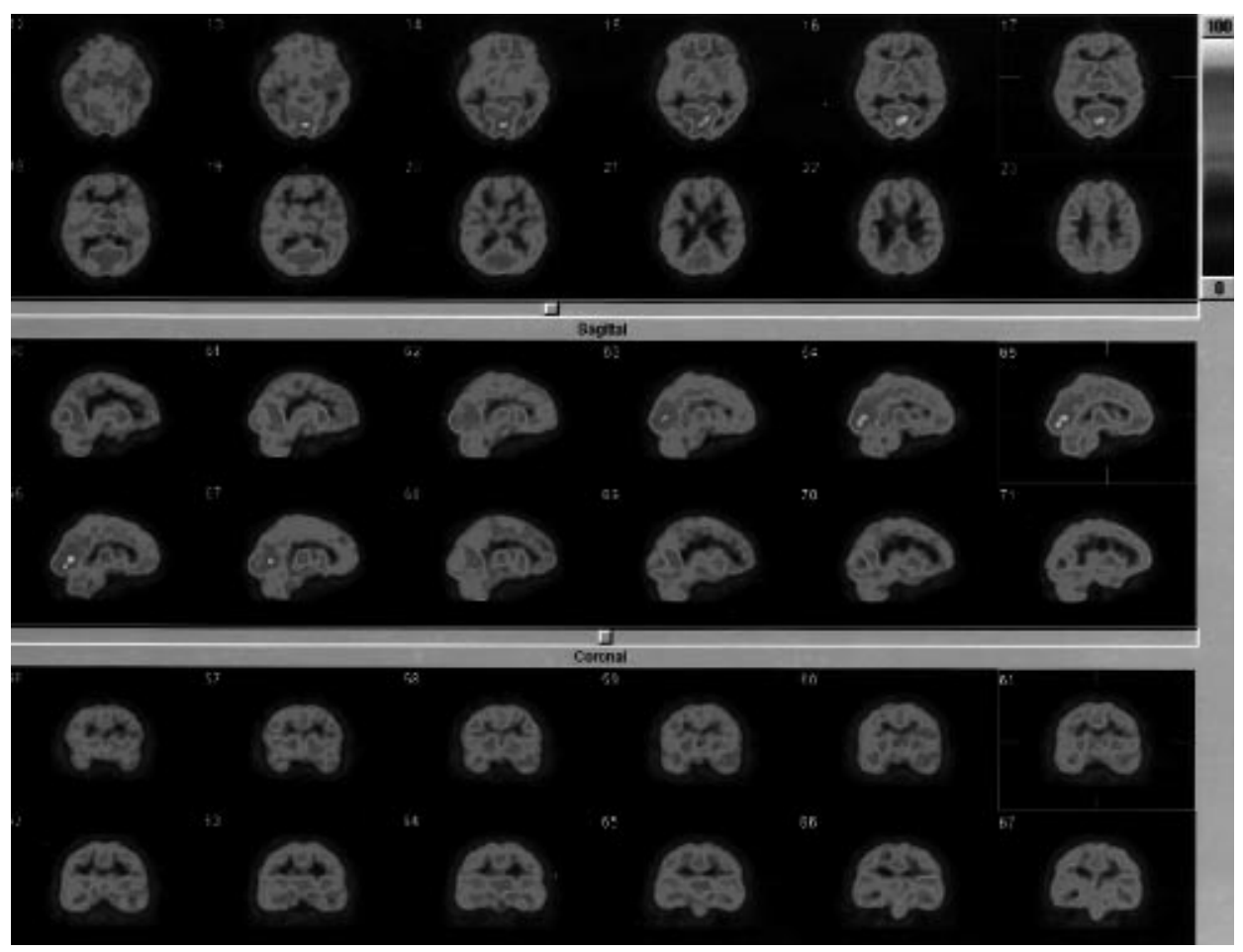

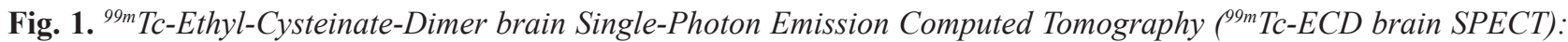
reconstructed transaxial, coronal and sagittal slices showed reduced perfusion radiotracer uptake in cortical frontal areas. Hypoperfusion was more evident in left frontal lobe. ${ }^{{ }^{2}}{ }^{99_{m}} T c-E C D$ uptake abnormalities were detected in the basal ganglia. 


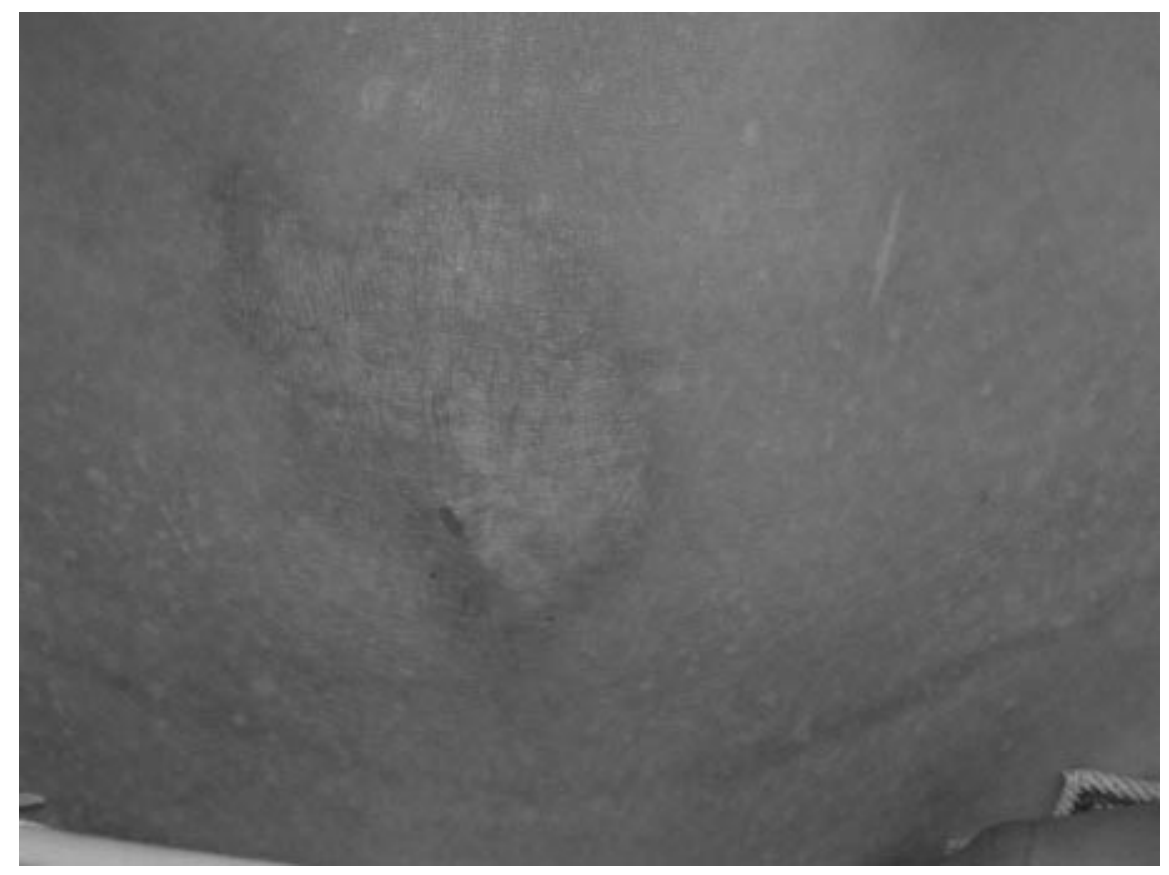

Fig. 2. Macroscopic characteristics of the lichenoid dermatitis in our Wilson disease patient: irregularly rounded erythematous lesion of non-photoexposed skin, located on the abdominal cutis and particularly in the umbilical region. Involved skin appears with an inflammatory lesion with characteristic violaceous polygonal flat-topped papules and plaques; the border is more erythematous than the rest of the lesion.

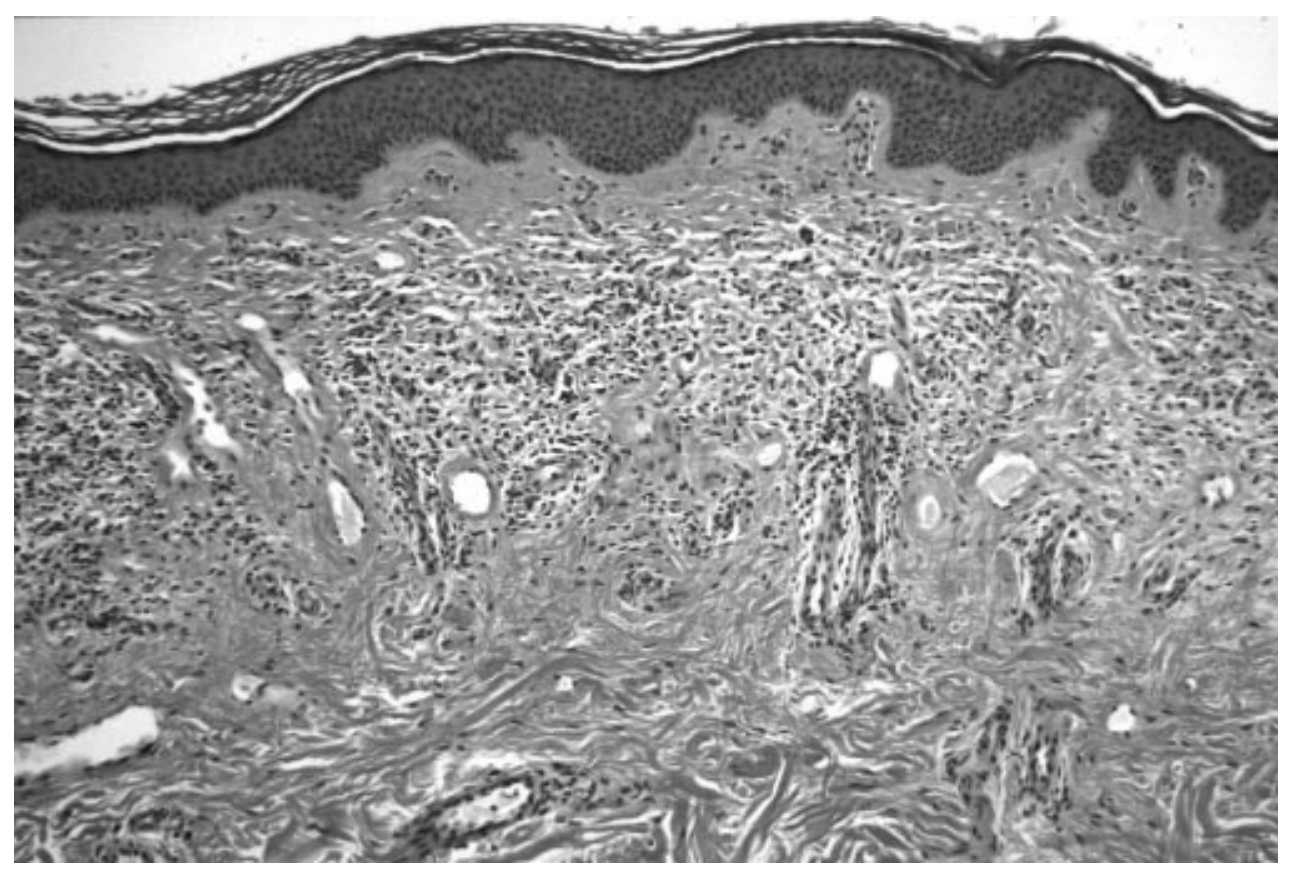

Fig. 3. Microscopic characteristics of the lichenoid dermatitis in our Wilson disease patient: lichenoid dermatitis with mild infiltrate in superficial and medial dermis. Histopathology of the biopsy specimen showed a dense band-like lymphocytic infiltrate at the dermoepidermal junction and superficial dermis. The infiltrate is less dense and less bandlike than in lichen planus itself and differs also from lichen planus by the presence of a few eosinophil cells (HE, 40X). 
(33). Specularly, in WD patients Eggers et al. (34) showed a significant negative correlation between the severity of depression and the density of presynaptic serotonin transporters (SERT) in the thalamushypothalamus region as measured by SPECT and $123 \mathrm{I}-2 \beta$-carbomethoxy-3 $\beta$ (iodophenyl)tropane (123I- $\beta$-CIT). In this connection, our case permits to hypothesize that in WD patients neuropsychiatric features could be still present even if copper accumulation is not evidenced by MRI and could be related to brain perfusion alterations.

In conclusion, the present paper describes for the first time the appearance of lichenoid lesions after chronic penicillamine treatment in WD. Since most of WD penicillamine-treated patients do not seem to develop this skin lesion, it could be conceivable that a specific genetic factor can be involved in drug response other than in specific clinical presentation (35-37). Further studies are needed for a better clarification of WD therapy and in particular to differentiate specific therapies for different WD phenotypes.

\section{ACKNOWLEDGEMENTS}

We would like to express our gratitude to the patient for making this publication possible.

We are grateful to Orphan Europe Srl, Segrate (Milan) for supplying the zinc acetate drug.

\section{REFERENCES}

1. Loudianos G. and J.D. Gitlin. 2000. Wilson's disease. Semin. Liver Dis. 20:353.

2. Leggio L., G. Addolorato, L. Abenavoli and G. Gasbarrini. 2005. Wilson's disease: clinical, genetic and pharmacological findings. Int. J. Immunopathol. Pharmacol. 18:7.

3. Roberts E.A. and M.L. Schilsky. 2003. AASLD practice guidelines. A practice guideline on Wilson's disease. Hepatology 37:1475.

4. Schilsky M.L., I.H. Scheinberg and I. Sternlieb. 1994. Liver transplantation for Wilson's disease: indications and outcome. Hepatology 19:583.

5. Spielberg C.D., R.L. Gorsuch and R.E. Lushene. 1983. Manual for the State and Trait Anxiety Inventory, ed. Consulting Psychologist Press. Paolo
Alto (CA), p.1.

6. Zung W.W., C.B. Richards and M.J. Short. 1965. A self-rating depression scale in outpatient clinic. Further validation of SDS. Arch. Gen. Psychiatry 37:847.

7. Addolorato G., E. Capristo, G. Ghittoni, C. Valeri, R. Mascianà, C. Ancona and G. Gasbarrini. 2001. Anxiety but not depression decreases in celiac patients after one-year gluten-free diet: a longitudinal study. Scand. J. Gastroenterol. 36:502.

8. Addolorato G., G. De Lorenzi, L. Abenavoli, L. Leggio, E. Capristo and G. Gasbarrini. 2004. Psychological support counselling improves glutenfree diet compliance in celiac patients with affective disorders. Aliment. Pharmacol. Ther. 20:777.

9. Brewer G.J., R.D. Dick, V.D. Johnson, J.K. Fink, K.J. Kluin and S. Daniels. 2001. Treatment of Wilson's disease with zinc XVI: treatment during the pediatric years. J. Lab. Clin. Med. 137:191.

10. Feliciani C., A. Verrotti, G. Coscione, P. Toto, F. Morelli, A. Di Benedetto, C. Salladini, F. Chiarelli and A. Tulli. 2003. Skin reactions due to antiepileptic drugs: several case-reports with long-term follow-up. Int. J. Immunopathol. Pharmacol. 16:89.

11. Cavalieri S., M. Rotoli, C. Feliciani and P. Amerio. 2005. Expression of the high-affinity laminin receptor $(67 \mathrm{kDa})$ in normal human skin and appendages. Int. $J$. Immunopathol. Pharmacol. 18:223.

12. Katta R. 2000. Lichen planus. Am. Fam. Physician 61:3319.

13. Feliciani C. and A. Tulli. 2002. Topical cyclosporin in the treatment of dermatologic diseases. Int. J. Immunopathol. Pharmacol. 15:89.

14. Abenavoli L., I. Proietti, L. Leggio, A. Ferrulli, L. Vonghia, R. Capizzi, M. Rotoli, P.L. Amerio, G. Gasbarrini and G. Addolorato. 2006. Cutaneous manifestations in celiac disease. World $J$. Gastroenterol. 12:843.

15. Ellgehausen P., P. Elsner and G. Burg. 1998. Druginduced lichen planus. Clin. Dermatol. 16: 325.

16. Levy R.S., M. Fisher and J.N. Alter. 1983. Penicillamine: review and cutaneous manifestations. J. Am. Acad. Dermatol. 8:548.

17. Blasberg B., J.L. Dorey, H.B. Stein, A. Chalmers and R.J. Conklin. 1984. Lichenoid lesions of the oral mucosa in rheumatoid arthritis treated with 
penicillamine. J. Rheumatol. 11:348.

18. Seehafer J.R., R.S. Rogers $3^{\text {rd }}$, C.R. Fleming and E.R. Dickson. 1981. Lichen planus-like lesions caused by penicillamine in primary biliary cirrhosis. Arch. Dermatol. 117:140.

19. Shyamal K.D. and R. Kunal. 2006. Wilson's disease: an update. Nature Clin. Pract. Neurol. 2:482.

20. Lee V.D., P.G. Northup and C.L. Berg. 2006. Resolution of decompensated cirrhosis from Wilson's disease with zinc monotherapy: a potential therapeutic option? Clin. Gastroenterol. Hepatol. 4:1069.

21. Walshe J.M. 1982. Treatment of Wilson's disease with trientine (triethylene tetramine) dichloride. Lancet 1:643.

22. Brewer G.J. 2001. Zinc acetate for the treatment of Wilson's disease. Expert. Opin. Pharmacother. 2:1473.

23. Marcellini M., V. Di Ciommo, F. Callea, R. Devito, D. Comparcola, M.R. Comparcola, M.R. Sartorelli, G. Carelli and V. Nobili. 2005. Treatment of Wilson's disease with zinc from the time of diagnosis in pediatric patients: a singlehospital, 10-year follow-up study. J. Lab. Clin. Med. 145:139.

24. Hoogenraad T.U. 2006. Paradigm shift in treatment of Wilson's disease: zinc therapy now treatment of choice. Brain Devel. 28:141.

25. Giagheddu M., G. Tamburini, M. Piga, P. Tacconi, A. Giagheddu, A. Serra, P. Siotto, L. Satta, L. Demelia and F. Marrosu. 2001. Comparison of MRI, EEG, EPs and ECD-SPECT in Wilson's disease. Acta Neurol. Scand. 103:71.

26. Komine Y., F. Shundo, N. Shirahata, K. Takahashi and T. Fujita. 1998. Single photon emission computed tomography (SPECT) in a patient with Wilson's disease. Jpn. J. Med. 27:309.

27. Schwarz J., K. Tatsch, T. Vogl, C.M. Kirsch, C. Trenkwalder, G. Arnold, T. Gasser and W.H. Oertel. 1992. Marked reduction of striatal dopamine D2 receptors as detected by 123IBZM-SPECT in a Wilson's disease patient with generalized dystonia. Mov. Disord. 7:58.

28. Keller R., R. Torta, M. Lagget, S. Crasto and B. Bergamasco. 1999. Psychiatric symptoms as late onset of Wilson's disease: neuroradiological findings, clinical features and treatment. Ital. J. Neurol. Sci 20:49.
29. Barthel H., D. Sorger, H.J. Kuhn, A. Wagner, R. Kluge and W. Hermann. 2001. Differential alteration of the nigrostriatal dopaminergic system in Wilson's disease investigated with [123I]ss-CIT and high-resolution SPET. Eur. J. Nucl. Med. 28:1656.

30. Barthel H., W. Hermann, R. Kluge, S. Hesse, D.R. Collingridge, A. Wagner and O. Sabri. 2003. Concordant pre- and post-synaptic deficits of dopaminergic neurotransmission in neurologic Wilson disease. Am. J. Neuroradiol. 24:234.

31. O'Connel R.A. 1995. SPECT brain imaging in psychiatric disorders: current clinical status. In Brain SPECT Imaging in Psychiatry. Grünwald F., S. Kasper, H.J. Biersack and H.J. Möller, eds. De Gruiter W, Berlin-New York, p. 35.

32. Addolorato G., D. Di Giuda, G. De Rossi, V. Valenza, M. Domenicali, F. Caputo, A. Gasbarrini, E. Capristo and G. Gasbarrini. 2004. Regional cerebral hypoperfusion in patients with celiac disease. Am. J. Med. 119:312.

33. Davidson R.J., H. Abercrombie, J.B. Nitschke and K. Putnam. 1999. Regional brain function, emotion and disorders of emotion. Curr. Opin. Neurobiol. 9:228.

34. Eggers B., W. Hermann, H. Barthel, O. Sabri, A. Wagner and S. Hesse. 2003. The degree of depression in Hamilton rating scale is correlated with the density of presynaptic serotonin transporters in 23 patients with Wilson's disease. J. Neurol. 250:576.

35. Leggio L., G. Addolorato, G. Loudianos, L. Abenavoli, M.B. Lepori, F.M. Vecchio, G.L. Rapaccini, S. De Virgiliis and G. Gasbarrini. 2006. A new mutation of Wilson's disease P-type ATPase gene in a patient with cirrhosis and coombspositive hemolytic anemia. Dig. Dis. Sci. 51:34.

36. Leggio L., G. Addolorato, G. Loudianos, L. Abenavoli and G. Gasbarrini. 2006. Genotypephenotype correlation of the Wilson disease ATP7B gene. Am. J. Med. Gen. 140A:933.

37. Leggio L., N. Malandrino, G. Loudianos, L. Abenavoli, M.B. Lepori, E. Capristo, S. De Virgiliis, G. Gasbarrini and G. Addolorato. (in press). Analysis of the T1288R mutation of the Wilson disease ATP7B gene in four generations of a family: possible genotype-phenotype correlation with hepatic onset. Dig. Dis. Sci. 